\title{
Alexitimia y oralidad dramatizada en las necesidades educativas especiales
}

\author{
Alexithymia and dramatized orality in the special educational needs
}

\author{
Ermel Morales \\ Escola Superior de Arte Dramática de Galicia
}

\begin{abstract}
Resumen
La Alexitimia $(\mathrm{a}=$ no, lexis $=$ palabras, timia $=$ sentimientos) es un desorden en la regulación de los afectos que se caracteriza por una incapacidad para identificar, describir y expresar sentimientos. La oralidad es el conjunto de competencias verbales vinculadas a la conducta comunicativa del individuo como transmisor de ideas. El objetivo es analizar los beneficios del entrenamiento expresivo, haciendo hincapié en aquellos que inciden positivamente en la autopercepción del lenguaje y las emociones. La Escala Toronto de Alexitimia (TAS-20) y la Escala de Alexitimia para Observadores (OAS) se correlacionan con la práctica de texto oral dramatizado en las necesidades educativas especiales.
\end{abstract}

\begin{abstract}
Alexithymia $(\mathrm{a}=$ no, lexis $=$ words, timia $=$ feelings $)$ is a disorder in the regulation of the affection that is characterized by an inability to identify, describe and express feelings. Orality is the set of verbal competencies linked to the communicative behavior of the individual as a transmitter of ideas. The objective is to analyze the benefits of expressive training, with emphasis on those who have a positive impact on the self-perception of the language and emotions. Correlates the Toronto alexithymia scale (TAS-20) and the Scale of Alexithymia for Observers (OAS) with the practice of oral text dramatized in special educational needs.

Keywords: Alexithymia, Language Arts, Special Education, Oral Interpretation
\end{abstract}

Estudiar aspectos relacionados con la comunicación a través de la alexitimia se presenta como un propósito poliédrico pues la palabra "alexitimia" refiere a un catálogo de rasgos clínicos que subyacen en determinados trastornos o pacientes (Cerezo, GarcíaMoja, Gándara y Hernández, 1988). La evaluación empírica basada en la Escala Toronto de Alexitimia en su versión española del Tas-20 (Martínez-Sánchez, 1996), sirve de demostrativo indirecto en la relación entre alexitimia y expresión. Los resultados obtenidos se contrastan con las valoraciones que se obtienen de la Escala de Alexitimia para Observadores (OAS), referente para discutir resultados en el marco de la evaluación externa y las necesidades educativas especiales. La elección es asociar la alexitimia al texto oral improvisado o aprendido. Los mecanismos asociados a la imaginación y a la creatividad entran en conflicto con la capacidad de simular emociones previamente transferidas por el proceso de dramatización de lo escrito. Se trata de aprender a gestionar las sensaciones físicas de una situación ficcionada desde el prisma educativo señalado por Vieites (2014).

Llamamos problemática de la paradoja al contraste entre la ausencia de palabras para los afectos y los beneficios de la expresión dramática. El hecho de reconocer afectos y poderlos expresar en palabras de manera inducida se contrapone al componente somático. El participante expuesto al juego dramático debe adaptarse a niveles de activación que pueden estar disociados de su realidad física, y ese mismo proceso ya contiene características cercanas a las sensaciones alexitímicas en sí. La actividad dramática ofrece un entrenamiento exhaustivo de consciencia. Recupera la capacidad innata del propio sujeto de ser partícipe de su creatividad y retentiva sensorial. El nivel de alexitimia repercute en la capacidad de conseguir dar expresividad a un texto oral. La incapacidad para expresarse con fluidez y el acto de forzar al individuo a confrontarse con su propia expresión de manera temporal, ofrece una visión descontextualizada en la que la subjetividad del participante cobra una nueva dimensión. Durante este proceso se exploran los mecanismos de la expresión, sean o no inherentes en el individuo. Adoptar como propio un lenguaje que no es producto de un pensamiento espontáneo implica, en cierto modo, una adaptación de la personalidad. En toda inmersión dramática, la personalidad guarda una relación directa con este proceso pues si bien el participante sigue siendo el mismo, se ve obligado a incorporar procesos de habla "no personales", sea a través de un guion de pautas de improvisación o través de un texto aprendido. Al adulterar de manera forzada las características verbales de la personalidad, se alteran eventualmente los procesos naturales de comportamiento de mente, cuerpo y voz. Se trata de una limitación dentro de la limitación, es decir, una herramienta a favor del analfabetismo expresivo. Las palabras se convierten en estresores emocionalmente represores pero también en estímulos emocionalmente activadores.

En el caso de las necesidades educativas especiales el reto es evaluar desde la subjetividad. Se analiza la conducta corporal y vocal como percepción psicofísica entre sonido y sentido para que el sujeto se relacione de manera consciente con su propia expresividad. La memorización significativa de partituras ajenas a la realidad del sujeto lo lleva a combatirse entre hacer suya la creatividad pactada o caer en una mera reproducción. La capacidad creativa a través del texto está ligada a la dificultad para describir sentimientos a los otros. El proceso por el cual el participante pretende corporalizar 
a través de la palabra dramatizada, implica profundizar en capacidades introspectivas para poder exponer emociones a la reflexión y al autoanálisis. En este sentido, trabajar con la inteligencia emocional (Goleman, 1998) influye en el manejo de la agilidad emotiva $y$ en la interiorización de situaciones liberadoras. A través de la experiencia dramática se intenta expresar verbalmente aspectos relacionados con la conciencia de uno mismo, la autorregulación de sensaciones, la motivación como espíritu de superación, la empatía con la expresividad del otro y el conjunto de habilidades sociales que desarrolla el individuo. Toda capacidad comunicativa está asociada a la expresión psíquica y a la expresión somática. Si nos hacemos esta pregunta: “¿cómo disociar lo que se dice de quién lo dice"? (Debray, 1996) entenderemos de qué manera la pretensión de comunicar choca con los malestares que aparecen durante el proceso dramático. Estas expresiones somáticas no son traumáticas sino producto de la propia desconexión que produce la disociación de las reacciones del cuerpo del sujeto y su capacidad para la conciencia corporal. La palabra materializa la representación de la angustia y de los afectos. Representa lo que existe para la mente debido a que los procesos de mentalización operan sobre la producción de la palabra representante. El uso de la expresión dramática como estimulación para desarrollar capacidades comunicativas aporta un trabajo de autopercepción que actúa como vía de expresión y canalización de emociones. Es por ello que este reajuste entre ficción y realidad debe ser procesado por el individuo teniendo en cuenta las premisas de intervención y revisando las reacciones fisiológicas de cada participante.

En las comprobaciones de Alexitimia y expresión (Morales, 2013) y recogidos todos los datos que se realizaron en distintos análisis estadísticos con el programa SPSS 19.0 para Windows, queda constancia de que un mayor número de sesiones de entrenamiento de conciencia oral repercute positivamente en una valoración menor de las connotaciones alexitímicas. Esto se constata en el factor 1 (identificar emociones), en el factor 2 (describirlas) y en el factor 3 (permanecer concentrado para identificarlas y describirlas). Habiéndose realizado el $100 \%$ total de test analizados, correspondiente a 275 sujetos, sólo un $13,5 \%$ se enmarca dentro de la clasificación "Si Alexitimia". El resto del porcentaje lo completa un 66, $2 \%$ de sujetos clasificados en "No Alexitimia" y el valor intermedio de "Baja Alexitimia" con un $20,4 \%$.

De esta manera, la correlación entre la práctica de interpretación y los niveles de alexitimia se sostiene mediante un instrumento de evaluación riguroso que mide la dificultad para identificar sentimientos y diferenciarlos de las sensaciones corporales o fisiológicas que acompañan la actividad emocional (ítems: 1, 3, 6, 7, 9, 13, 14), la dificultad para describir los sentimientos a los demás (ítems: $2,4,11,12,17)$ y el estilo de pensamiento orientado a lo externo (ítems: 5, 8, 10, 15, 16, 18, 19, 20). Esta es la relación establecida entre problemáticas expresivas y las habilidades comunicativas trabajadas a través de lo dramático:
1. A menudo me encuentro confundido sobre cuál es la emoción que estoy sintiendo

La interpretación textual aproxima al individuo a sensaciones que le son sugeridas. Es preciso atender a determinados procesos inadecuados de conducta, es decir, detectar si se advierte que la actitud que se está dando no corresponde con ninguna causa justificada o que se pueda captar de manera lógica.

2. Me es difícil encontrar las palabras exactas para describir mis sentimientos

Polavsky (1945) hablaba del carácter vago e impersonal del discurso oral de los pacientes psicosomáticos que él estudiaba. La relatividad de la expresión oral se centra en el valor que corresponde a cada palabra del discurso. La tendencia a improvisar verbalmente es un factor que determina la integración de estructuras mentales asociadas al lenguaje.

3. Tengo sensaciones físicas que ni los médicos las entienden

Mediante ejercicios de interpretación textual se pueden trabajar las sensaciones paralelas a una simple acciónreacción, entendida como adaptabilidad de la expresividad física y vocal a los estímulos. En esta fase es importante que el participante entienda que no todo lo que le ocurre al cuerpo se puede mostrar.

4. Soy capaz de describir mis sentimientos con facilidad

La memorización no debe estar asociada a la mecanización de palabras aprendidas. Estas palabras y situaciones surgen de la necesidad de jugar momentos que podrían simulan producirse por primera vez. El juego dramático debe mostrar al participante la relación entre esfuerzo comunicativo y eficacia expresiva.

5. Prefiero analizar los problemas en vez de describirlos o explicarlos

La gestión de la autoestima, tal y como indicaba Goleman (1996), es fundamental a la hora de dar rienda suelta a las problemáticas relacionadas con el trabajo de expresión. Trabajar la autoestima es una consecuencia positiva producto del placer de tomar conciencia de los propios avances individuales. Esta motivación no está reñida con la insistencia de establecer un trabajo marcado por la responsabilidad y la correcta utilización de las directrices. Intentar racionalizar los problemas limita la capacidad del participante, evitando que este se enfrente al trabajo de manera activa.

6. Cuando estoy mal no sé si estoy triste, asustado o enfadado

Trabajar la precisión de sensaciones respecto a la expectativa del receptor, ayuda a vincular la concordancia 
de las sensaciones con la lógica de los acontecimientos. Esto potencia la capacidad de concreción del participante.

7. A menudo estoy hecho un lío con las sensaciones que noto en mi cuerpo

La relación entre la expresión oral y la expresión corporal ofrece la oportunidad de profundizar en aspectos técnicos relativos a la fonación y a la incidencia de la palabra en el cuerpo. De esta manera no sólo se desarrolla la capacidad de entrenar la articulación y sino múltiples aspectos de la mecánica fisiológica.

8. Prefiero dejar que las cosas pasen en vez de analizar por qué han ocurrido así

Es conveniente entrenar el vínculo entre rendimiento y nivel de activación: detectar si el desgaste físico va en relación a lo que se quiere conseguir en determinados momentos. La retentiva es fundamental para hacer que el sujeto sea más consciente de las sensaciones vivenciadas.

\section{Tengo sentimientos que no puedo identificar}

Ante la dificultad para identificar sentimientos los participantes se ven expuestos a asimilar estados emocionales. Esa incomodidad somática es un intento reiterado de escapar del análisis acerca de los propios sentimientos y supone una evidente lucha con la limitación de la imaginación.

10. Es esencial estar en contacto y sentir emociones o sentimientos

La expresión dramática incrementa la interacción de los participantes y es un acto comunicativo con el que se puede lograr un ambiente de trabajo lúdico con fines pedagógicos. La concentración establece un clima que favorece el contacto entre participantes.

11. Me es difícil describir o explicar lo que siento sobre la gente

El entrenamiento expresivo es un trabajo de cooperación y comunicación grupal. Si bien Freedman y Sweet (1954) llamaban "iletrados emocionales" a sus pacientes con problemáticas, las respuestas subjetivas a los estímulos asociados a la interpretación provocan cambios y reajustes que deben potenciar la apertura a la experiencia y la empatía.

12. La gente me pide que explique con más detalle mis sentimientos

Siempre habrá participantes que no sean capaces de desprenderse del impacto afectivo en las situaciones de estrés emocional y que traten toda situación como normales (Groen y Bastiaans, 1951). Mediante la expresión dramática se entrena la consciencia acerca de las reacciones fisiológicas. La perspectiva analítica encamina al individuo a definir mejor la propia simulación actuada y a ser capaz de hacer autocrítica en público.

13. No sé qué está pasando en mi interior, dentro de mí

Si bien en terapias como la de Swiller (1988) el grupo ofrece un ambiente en el que los otros evocan y demuestran afectos personales manejables, la expresión dramática no solamente abarca el componente de extroversión del individuo, sino que refuerza la parte más individualizada de su mundo interior.

\section{A menudo no sé por qué estoy enfadado}

Warnes (1988) propone que para una buena selección de medios estratégicos se debe procurar analizar particularmente la magnitud de los acontecimientos de vida del sujeto alexitímico. En la actividad dramática suelen aparecer malestares vinculados al propio mecanismo de defensa de individuo. Estas situaciones estresantes son producidas por la frustración que conlleva el propio proceso de prueba-error.

15. Prefiero hablar con la gente de sus actividades diarias más que de sus sentimientos

En este sentido, la capacidad de vincular cuerpo y voz en la oralidad dramatizada, implica que el sujeto comprenda que una partitura de acciones o el desarrollo completo de inicio a fin de una escena pactada no se tome como mecánica formal sin contenido emocional.

16. Prefiero ver en la TV programas superficiales de entretenimiento en vez de complicados dramas psicológicos

La menor o mayor tendencia a concebir la expresión dramática como juego superfluo, suele ir muy ligada al miedo a la exposición emocional. En otros casos responde también a una dinámica de no afrontamiento que salva al individuo de encontrase con sus propias barreras expresivas.

17. Me es difícil revelar mis más profundos sentimientos, incluso a mis amigos íntimos

Los participantes con problemas de comunicación encontraran en el marco de actividad dramática una situación idónea para relacionarse. Los alexitímicos rara vez buscan terapia por su propia voluntad (Swiller, 1988). El interés de este estudio es abogar por una práctica dramatizada de textos que incite a potenciar la comunicación de afectos. Sin interacción no hay diálogo, sin dialogo no hay situación compartida. Es un pacto que va más allá de la confianza, pues la intimidad se presupone no se propone.

18. Puedo sentirme cercano a alguien, comprender sus sentimientos, incluso en momentos de silencio 
La alexitimia se caracteriza por la toma de determinadas decisiones que se basan en razones más prácticas que sentimentales. La dimensión hedónica está prácticamente anulada porque la información emocional depende de un básico me gusta-no me gusta. En el acto teatral las reacciones inmediatas y de acción automática se entrelazan con el comportamiento reflejo del individuo.

19. Me resulta útil examinar mis sentimientos para resolver problemas personales

Partiendo de las premisas de conciencia emocional de Lane y Schwartz (1987), que postulan la existencia de una secuencia de desarrollo cognitivo en 5 pasos que varían desde el más primitivo (reflexivo-sensorio-motor) al más avanzado (operacional-formal), la actividad dramática ofrece la posibilidad de reconocer actitudes o de trasladarlas al propio juego dramático.

20. Buscar el significado profundo de las películas distrae de la diversión que se pueda sentir viéndolas simplemente, sin complicarse

La alexitimia se asocia a procesos imaginativos restringidos. Aunque la imaginación es la creación de nuevas imágenes que no pertenecen a la vivencia sensorial, también se debe potenciar la capacidad para recuperar imágenes en la mente que pertenecen a aspectos concretos de la memoria sensorial de cada sujeto. Ruesch (1948) hablaba de la pobreza simbólica del paciente psicosomático. En este contexto, el texto oral estimula la experiencia sensorial y conserva el recuerdo de aspectos concretos para que formen parte de la imaginación. De esta manera, la imaginación conectará con las emociones del participante.

Para complementar este estudio es preciso contar también con el punto de vista externo. Repasamos aquí las premisas de la Escala de Alexitimia para Observadores (Haviland, 1996), teniendo en cuenta la incidencia de la expresión dramática como vía canalización de emociones (Morales, 2010). La OAS se divide en cinco subescalas asociadas a los aspectos prosódicos del lenguaje emocional (entonación, cadencia, melodía).

1. Subescala 1: distante. El análisis externo determina si la persona es cálida, compasiva y buena relacionándose. Si es sensible hacia las personas, si le gusta sentirse cercana o tener amigos próximos. Esta subescala pregunta acerca de si al participante le gusta explorar sentimientos, le gusta tocar y ser tocado. Por último, analiza el grado de flexibilidad, imaginación y creatividad.

Se trabaja la incidencia del grupo en el participante: interacción, identidad centrada en el concepto "nosotros" y evasión del "yo". Las condiciones de trabajo siempre han de incluir: aceptación de los miembros, integración de las presencias rotativas, adaptación a las tareas colectivas, mejora de la escucha activa $y$, sobretodo, libertad para participar activamente en los planteamientos grupales.
2. Subescala 2: no introspectivo. Persona que se hunde ante la adversidad, que se muestra confundida ante el estrés, que se frustra ante al enfrentarse a lo incierto, que tiene fuertes emociones que no puede explicar, que parece no tener metas y que necesita conocerse a sí misma para comprenderse.

Es necesario calibrar la capacidad atencional para poder detectar si tienen más o menos capacidad de estar en disposición expresiva, es decir, si consiguen expresar lo que quieren con mayor o menor fluidez. Es preciso también observar cómo captan la información recibida y si tienen tendencia a la omisión perceptiva. La confluencia de ambas capacidades atencionales es la que marca la adaptación al estímulo, es decir, es la que deja en evidencia si reaccionan con una conducta óptima a las situaciones o de manera sobre-estimulada.

3. Subescala 3: somatización. Se formula la obsesión con la salud. Somatiza el que habla mucho del dolor, el que se preocupa en exceso por su cuerpo, el que tiene problemas físicos difíciles de tratar y el que tiene reacciones físicas asociadas al estrés.

Cada metodología de trabajo debe ser proyectada de manera que se consigan los fines expresivos y de creación esperados pero siempre desde el prisma del bienestar del participante. Si se pone de manifiesto una incomodidad reiterada, no habrá motivación y sin motivación no habrá implicación.

4. Subescala 4: sin sentido del humor. Se confrontan las reacciones con los sujetos que están de buen humor, que saben hacer reír y que son juguetones. Al alexitímico nada le parece estimulante sino aburrido, soso y nada interesante.

No se tratará solamente de potenciar, atendiendo a la evolución del proceso de intervención, las competencias adquiridas por los participantes sino también de animarlo a buscar nuevas posibilidades expresivas. Es fundamental que la actividad transcurra con los participantes disfrutando de ella, ocupados en despreocuparse.

5. Subescala 5: rígido. Se observa si la persona es demasiado auto-controlada, si cree firmemente que debe seguir las reglas siendo inflexible y si ve las cosas o blancas o negras, reprimiéndose de disfrutar sin que nadie le obligue a ello.

Al contar con la rigidez del participante es preciso usar una metodología hetero-didáctica pero, a su vez, dialéctica, pues estará centrada en la cohesión del grupo. Lejos de lo dogmático o impositivo, se buscará empatizar con las necesidades afectivas del grupo, atendiendo a la simplicidad de las estrategias, a la participación activa de todos los miembros del grupo, a la adecuación de la cronología "tiempo-inversión energética" y a la preocupación por seguir el proceso de manera personalizada. 
La actividad teatral es una herramienta de desarrollo personal (Vieites, 2014) para las necesidades expresivas. La praxis del texto oral dramatizado fomenta la autoconciencia y la confrontación con los mecanismos de defensa no expresivos vinculados a la Alexitimia.

\section{Referencias}

Debray, R. (1996). Clinique de l'expression somatique. Paris: Delachaux et Niestlé.

Freedman, M. B., \& Sweet, B. S. (1954). Some specific features of group psychotherapy and their implication for selection of patients. International Journal of Group Psychotherapy, 4, 355-368.

Groen, J. J., \& Bastiaans, J. (1951). Grondslagen der klinische psychosomatiek [fundamentals of clinical psychosomatics]. Haarlem: Erven F. Bohn.

Goleman, D.(1996). Inteligencia emocional = emotional intelligence español. Barcelona: Kairós.

Goleman, D. (1998). Working with emotional intelligence. London: Bloomsbury.

Haviland, M. G., Sonne, J. L., \& Kowert, P. A. (2004). Alexithymia and psychopathy: Comparison and application of california Q-set prototypes. Journal of Personality Assessment, 82(3), 306-316. http://doi.org/ 10.1207/s15327752jpa8203_06

Lane, RD, y Schwartz, GE (1987). Los niveles de conciencia emocional: Una teoría del desarrollo cognitivo y su aplicación a la psicopatología. American Journal of Psychiatry, 144, 133-143. Disponible en http://psycnet.apa.org/psycinfo/198718836-001

Martínez-Sánchez, F. (1996). Adaptacion española de la escala de alexitimia de Toronto (TAS-20). Clínica y Salud, 7(1), 19-32.

Morales, E. (2013). Tesis doctoral: Alexitmia y expresión. Departamento de Ciencias de la Educación, el Lenguaje, la Cultura y las Artes. Disponible en http://hdl.handle.net/10115/12309

Morales, E. (2010 a). O teatro como via de expressao nas necessidades educativas especiais. En O Estado do Teatro en Portugal. Intervenção - Associação Para a Promoção e Divulgação Cultural. Coor. Dantas Lima Pereira, J.; De Sousa Lopes, M.;Pascual, R. Chaves, Portugal. 209-216.

Polavsky, A. (1945). Over psychosomatiesche toestanden. Geneesk, 42, 215.

Ruesch, J. E. (1948). The infantile personality. Psychosomatic Medicine, , 10-13.

Swiller, H. I. (1988). Alexithymia - treatment utilizing combined individual and group-psychotherapy. International Journal of Group Psychotherapy, 38(1), 47-61.

M Vieites, M. F. (2014) La educación teatral: una propuesta de sistematización. Revista Interuniversitaria, Ediciones Universidad de Salamanca. http://dx.doi.org/10.14201/teoredu201426177101

Warnes, H. (1988). Alexithymia and related states. Psychiatric Journal of University of Ottawa, 13(3), 127-135. Disponible en http://psycnet.apa.org/psycinfo/1989-22670-001 